\title{
Influence of pre-training predator stress on the expression of c-fos mRNA in the hippocampus, amygdala, and striatum following long-term spatial memory retrieval
}

\author{
Michael B. VanElzakker ${ }^{1 \dagger}$, Phillip R. Zoladz ${ }^{2}$,Vanessa M. Thompson', Collin R. Park ${ }^{3,4,6}$, Joshua D. Halonen ${ }^{3,4,6}$, \\ Robert L. Spencer ${ }^{1}$ and David M. Diamond ${ }^{3,4,5,6 *}$
}

1 Department of Psychology and Neuroscience, University of Colorado, Boulder, CO, USA

2 Department of Psychology and Sociology, Ohio Northern University, Ada, OH, USA

${ }^{3}$ Research and Development Service, James A. Haley Veterans' Hospital, Tampa, FL, USA

${ }^{4}$ Department of Psychology, University of South Florida, Tampa, FL, USA

${ }^{5}$ Department of Molecular Pharmacology and Physiology, University of South Florida, Tampa, FL, USA

${ }^{6}$ Center for Preclinical and Clinical Research on Post-traumatic Stress Disorder, University of South Florida, Tampa, FL, USA

\section{Edited by:}

Shigeyoshi Itohara, RIKEN Brain

Science Institute, Japan

\section{Reviewed by:}

Sumantra "Shona" Chattarii, National Centre for Biological Sciences, India

Thomas Mchugh, RIKEN Brain Science Institute, Japan

\section{*Correspondence:}

David M. Diamond, Department of Psychology, PCD 4118G, University of South Florida, 4202 E. Fowler Avenue,

Tampa, FL 33620, USA.

e-mail:ddiamond@usf.edu

${ }^{+}$Current address:

Michael B. VanElzakker, Department of Psychology, Tufts University, Medford, MA, USA
We have studied the influence of pre-training psychological stress on the expression of $c$-fos mRNA following long-term spatial memory retrieval. Rats were trained to learn the location of a hidden escape platform in the radial-arm water maze, and then their memory for the platform location was assessed $24 \mathrm{~h}$ later. Rat brains were extracted 30 min after the 24-h memory test trial for analysis of c-fos mRNA. Four groups were tested: (1) Rats given standard training (Standard); (2) Rats given cat exposure (Predator Stress) 30 min prior to training (PreTraining Stress); (3) Rats given water exposure only (Water Yoked); and (4) Rats given no water exposure (Home Cage). The Standard trained group exhibited excellent $24 \mathrm{~h}$ memory which was accompanied by increased $c$-fos mRNA in the dorsal hippocampus and basolateral amygdala (BLA). The Water Yoked group exhibited no increase in c-fos mRNA in any brain region. Rats in the Pre-Training Stress group were classified into two subgroups: good and bad memory performers. Neither of the two Pre-Training Stress subgroups exhibited a significant change in c-fos mRNA expression in the dorsal hippocampus or BLA. Instead, stressed rats with good memory exhibited significantly greater $c$-fos mRNA expression in the dorsolateral striatum (DLS) compared to stressed rats with bad memory. This finding suggests that stressed rats with good memory used their DLS to generate a non-spatial (cue-based) strategy to learn and subsequently retrieve the memory of the platform location. Collectively, these findings provide evidence at a molecular level for the involvement of the hippocampus and BLA in the retrieval of spatial memory and contribute novel observations on the influence of pre-training stress in activating the DLS in response to long-term memory retrieval.

Keywords: rat, c-fos, hippocampus, striatum, amygdala, spatial memory

\section{INTRODUCTION}

A major goal in the study of the neurobiology of memory is to determine aspects of neural activity that are associated with different components of cognitive processes, such as the acquisition, consolidation, and retrieval phases of memory processing. The study of experience-dependent immediate early gene expression has proven to be a valuable tool toward achieving this goal. The prototypical immediate early gene $c$-fos is transcribed in neurons within minutes after stimulation by various depolarizing and neurotrophic intercellular signals (Greenberg et al., 1986; Kovacs, 2008), and the rapid degradation of $c$-fos mRNA ensures that its expression represents recent changes in neuronal activation (Shyu et al., 1991). Most importantly, transcription of the $c$-fos gene is not merely a marker of increased neural activity; increased expression of $c$-fos mRNA appears to reflect the initiation of an intracellular cascade of molecular events which are essential for the development of neuroplasticity (Herdegen and Leah, 1998; Kubik et al., 2007).
Much of the research linking neuroplasticity to memory has focused on the hippocampus (Szapiro et al., 2002; Miyamoto, 2006; Bekinschtein et al., 2008). In rodents, this temporal lobe structure plays a critical role in spatial learning and memory (Morris et al., 1982, 1986; Guzowski and McGaugh, 1997; Kesner et al., 2004; Martin and Clark, 2007; Bird and Burgess, 2008). Although most of the work has focused on the necessary role of the hippocampus in memory formation, research has also demonstrated an involvement of the rodent (Riedel et al., 1999; Corcoran and Maren, 2001; Jezek et al., 2002; Szapiro et al., 2002; Micheau et al., 2004; Sutherland et al., 2010) and human (Dolan and Fletcher, 1999; Bosshardt et al., 2005; Rekkas and Constable, 2005; Moscovitch et al., 2006; Cabeza and St Jacques, 2007; Nadel et al., 2007; Spiers and Maguire, 2007a,b) hippocampus in long-term memory retrieval.

In molecular analyses of memory, numerous studies have examined $c$-fos gene expression patterns in the hippocampus of rodents during memory formation in various tasks, including 
spatial learning tasks (Vann et al., 2000; Guzowski et al., 2001; He et al., 2002; Teather et al., 2005; Shires and Aggleton, 2008). Most of these studies monitored $c$-fos gene expression by measuring Fos protein, the $c$-fos gene product. In general, these studies found marked increases in Fos expression with initial training, and in some cases, the extent of Fos expression has been positively correlated with the spatial processing demands of the task (Gall et al., 1998; Vann et al., 2000; Colombo et al., 2003).Few studies, however, have examined immediate early gene expression associated with memory retrieval, and these studies assessed Fos protein expression after re-exposure to a conditioned fear context. For example, several studies have reported increased immediate early gene expression in the hippocampus following contextual, but not cued, fear memory retrieval (Hall et al., 2001; Strekalova et al., 2003; Frankland et al., 2004). Thus, there is an insufficient understanding of how the hippocampus, as well as other brain structures, are involved in the retrieval of spatially relevant information.

In the present study, we investigated hippocampal $c$-fos gene expression patterns associated with the retrieval of spatial information (i.e., remembering the location of a hidden escape platform in a water maze). We also examined how exposure to acute psychological stress prior to spatial learning affected long-term $(24 \mathrm{~h})$ spatial memory and the expression of $c$-fos mRNA at the time of retrieval. The stress component of the current work is based on our studies which have shown that rats exposed to a cat (predator stress) exhibited a suppression of hippocampal synaptic plasticity (Mesches et al., 1999; Vouimba et al., 2006) and an impairment in spatial learning and memory (Diamond et al., 1999; Woodson et al., 2003; Park et al., 2006, 2008; Conboy et al., 2009). We have also shown previously that acute predator stress was associated with a suppression of learning-induced increases in phosphorylated CaMKII (Zoladz et al., 2011) and neural cell adhesion molecules (NCAMs; Sandi et al., 2005), as well as a blockade of morphological (dendritic spine) plasticity (Diamond et al., 2006) in the hippocampus. Overall, our findings are consistent with a broad range of research indicating that stress can produce adverse effects on hippocampal functioning (Lupien and Lepage, 2001; McEwen, 2001; Kim and Diamond, 2002; Sandi, 2004; Joëls et al., 2006; Packard, 2009).

In the current study we have extended our research on stress, memory, and hippocampal function by examining the influence of acute predator stress occurring prior to learning on the expression of $24 \mathrm{~h}$ spatial memory retrieval and $c$-fos mRNA. We have tested two related hypotheses: (1) Under the standard (non-stress) training condition, retrieval of long-term spatial memory would be accompanied by an increase in the transcription of $c$-fos mRNA in the hippocampus; and (2) Under the pre-training stress condition, retrieval of long-term spatial memory would be impaired and there would be an absence of an increase in the transcription of $c$-fos mRNA in the hippocampus. In addition, because stress changes the manner in which the brain processes information (Bisaz et al., 2009; Packard, 2009; Schwabe et al., 2010b), we included an assessment of the transcription of $c$-fos mRNA in non-hippocampal brain structures in response to memory retrieval in stressed rats. Overall, this study was designed to provide novel information on how pre-training stress affects long-term memory retrieval, and how successful versus unsuccessful retrieval may be related to the expression of $c$-fos gene transcription in different brain structures.

\section{MATERIALS AND METHODS SUBJECTS}

The subjects used in this experiment were adult male SpragueDawley rats (250-275 g; Charles River Laboratories). The animals were housed on a 12/12 h light dark schedule (lights on at 0700 hours) in Plexiglas cages (two per cage) with food and water provided ad libitum. Colony room temperature and humidity were maintained at $20 \pm 1^{\circ} \mathrm{C}$ and $60 \pm 3 \%$, respectively. All rats were given 1 week to acclimate to the colony room environment before any experimental manipulations took place. The rats were brought to the laboratory's water maze training room and handled for 2-3 min each during each of the last 3 days of the 1-week acclimation period. Behavioral manipulations were conducted between 0800 and 1300 hours and were always preceded by $30 \mathrm{~min}$ of acclimation to the testing environment. All experimental procedures were approved by the Institutional Animal Care and Use Committee at the University of South Florida.

\section{RADIAL-ARM WATER MAZE}

The radial-arm water maze (RAWM) was used to test spatial learning and memory and has been described at length in previous publications (Diamond et al., 1999, 2006; Woodson et al., 2003; Sandi et al., 2005; Park et al., 2006, 2008; Zoladz et al., 2006). Briefly, the RAWM consists of a black, galvanized stainless steel round tank (168 cm diameter, $56 \mathrm{~cm}$ height, $43 \mathrm{~cm}$ depth) filled with water $\left(22^{\circ} \mathrm{C}\right)$. Six V-shaped stainless steel inserts $(54 \mathrm{~cm}$ height, $56 \mathrm{~cm}$ length) were placed in the tank, forming six swim arms radiating from an open central area. A black, plastic platform $(12 \mathrm{~cm}$ diameter) was fixed in place $1 \mathrm{~cm}$ below the surface of the water at the end of one arm (referred to as the "goal arm"). The walls in the maze training room were different shades of gray or white, each approximately $1 \mathrm{~m}$ from the edge of the water tank. A door with a small window which was covered with a poster was in one corner of the room. The only source of light from within the room was from a fixture with a $40-\mathrm{W}$ incandescent bulb, with the light directed toward the wall in a corner of the room.

At the start of each trial, rats were released into one arm (referred to as the "start arm") facing the center of the maze. The start arm was pseudorandomly changed after each trial so that it was never the same for two consecutive trials. If, during any trial, a rat did not locate the hidden platform within $1 \mathrm{~min}$, it was gently guided to the platform by the experimenter. Once a rat found or was guided to the platform, it was left there undisturbed for $15 \mathrm{~s}$ before beginning the next trial.

Spatial learning and memory were measured by counting the number of arm entry errors that rats made on each trial. An arm entry was operationally defined as a rat passing at least halfway down the arm. For each trial, the experimenter recorded both the number of arm entry errors and the latency for the rat to find the hidden platform. An arm entry error consisted of a rat entering one of the non-goal arms or, very rarely, a rat entering and exiting the goal arm without climbing onto the platform.

All rats receiving standard water maze training were given 12 consecutive acquisition trials in the RAWM, and then they were returned to their home cages. One hour later the rats were given six additional trials, which served as a short-term memory test, and provided additional training (Figure 1). Training data were 


\section{Timeline and Procedures}

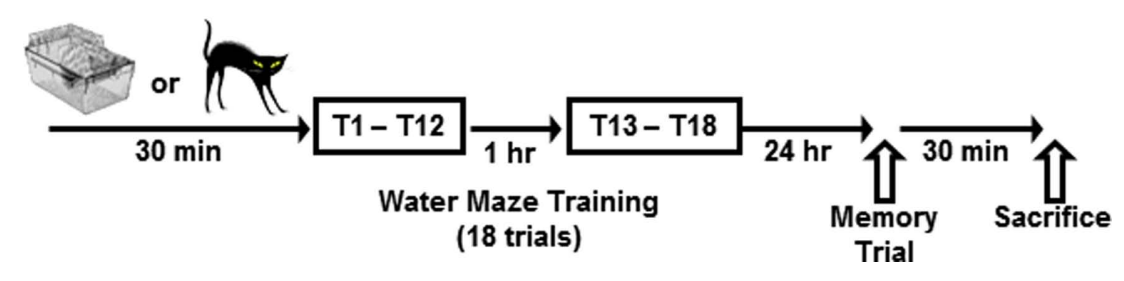

FIGURE 1 | Experimental timeline. The experimental procedures took place over 2 days. On day 1, rats were brought to the laboratory and then remained in their home cages (Standard Training) or were placed in close proximity to a cat (Pre-Training Stress) for 30 min immediately before training in the radial-arm water maze. The training protocol on Day 1 consisted of a total of 18 trials of training which were administered in 12 sequential trials (T1-T12), followed $1 \mathrm{~h}$ later by 6 more sequential trials (T13-T18). Water maze performance data (errors/trial) were averaged in two trial blocks for data analysis and presentation. Twenty-four hour later, all rats were given a single memory test trial to measure their long-term memory for the hidden platform location. Thirty minutes following the memory test trial, the rats were rapidly decapitated, and their brains were extracted for processing analyzed as the mean arm entry errors for training blocks of two consecutive trials. Twenty-four hour later, the rats were given a single test trial to assess their long-term memory for the hidden platform location.

\section{STRESS MANIPULATION}

To induce predator stress, rats were first placed in small Plexiglas boxes $(28 \mathrm{~cm} \times 9 \mathrm{~cm} \times 14 \mathrm{~cm})$, with multiple air holes in the top. The rats within the boxes were then placed for $30 \mathrm{~min}$ in a large cage $(57 \mathrm{~cm} \times 57 \mathrm{~cm} \times 76 \mathrm{~cm})$, which contained an adult female cat. The Plexiglas box prevented any physical contact between the cat and rats but enabled the rats to be exposed to all other sensory stimuli, such as the sight, smell, and sounds associated with the cat. Moist cat food was smeared on top of the Plexiglas box, which induced the cat to direct its attention toward the rats.

\section{TREATMENT GROUPS AND BEHAVIORAL PROCEDURE}

Four groups of rats were included in the present experiment: standard, Water Yoked, Pre-Training Stress, and Home Cage. Rats in the Water Yoked condition $(n=8)$ were given water maze exposure equivalent in time to the trained groups. The rats in this group received 19 total trials with the mean time per trial equal to that of the Standard and Pre-Training Stress groups. However, the rats in the Water Yoked group were not trained to learn the location of a hidden platform. Instead, for the Water Yoked group, a hidden platform was located in the water maze at the end of one arm, but if a rat located the platform on any given trial, the platform was moved to the opposite side of the maze on the next trial [rats in this group located the hidden platform on $1.63( \pm 0.63)$ trials out of the total of 19 trials]. Thus, the Water Yoked paradigm facilitated purposive swimming behavior by rats, but since the platform was not in a constant location, rats in this group were unable to form a memory for the platform location. This control group was included because a Home Cage control group alone is not adequate for distinguishing learning and memory effects, per se, from sensorimotor aspects of performance of the task which can affect immediate early gene expression (Shires and Aggleton, 2008).

Rats in the Pre-Training Stress condition $(n=16)$ were given standard training in the RAWM, with the addition of predator stress for $30 \mathrm{~min}$ immediately prior to water maze training. We found that rats in the Pre-Training Stress group exhibited a broad range of errors in their $24 \mathrm{~h}$ memory retrieval performance; individual rats in the Pre-Training Stress group committed from 0 to 6 errors. In a post hoc analysis we also found that half of the stressed rats exhibited excellent memory ( 0 or 1 error) and the other half exhibited poor memory ( $\geq 2$ errors; range $2-6$ errors). We therefore split the behavioral and $c$-fos mRNA data from the Pre-Training Stress group into two subgroups based on Good $(n=8)$ or $\operatorname{Bad}(n=8) 24$ h memory performance. Twice as many rats were assigned to the Pre-Training Stress group than were assigned to the other groups to increase the statistical power for analysis of the post hoc split of the Pre-Training Stress group into the Good and Bad memory subgroups.

Rats in the Home Cage condition $(n=8)$ were brought to the RAWM test room on both the training and memory testing days where they were given handling, but they were not exposed to the water.

\section{CORTICOSTERONE RADIOIMMUNOASSAY}

Thirty minutes after completion of the 24-h memory test, or at the equivalent time of day for the Home Cage group, rats were taken individually into an adjacent room where they were rapidly decapitated. A sample of trunk blood was then collected for the analysis of corticosterone. After clotting at room temperature, the blood was centrifuged, the serum was extracted and stored at $-80^{\circ} \mathrm{C}$ and then (along with the brain tissue) shipped to the University of Colorado at Boulder, where the samples were assayed by three co-authors (Michael B. VanElzakker, Robert L. Spencer, Vanessa M. Thompson) who were blind to the behavioral manipulations. Total serum corticosterone levels were determined by radioimmunoassay, as previously described (Ginsberg et al., 2003).

\section{C-FOS mRNA IN SITU HYBRIDIZATION}

The brains were rapidly extracted and flash-frozen in isopentane which was chilled between -30 and $-40^{\circ} \mathrm{C}$ with dry ice. The brains were then stored at $-80^{\circ} \mathrm{C}$, and subsequently shipped to the University of Colorado at Boulder, where they were processed for in situ hybridization for $c$-fos mRNA. Coronal sections ( $10 \mu \mathrm{m}$ thick) were obtained with a cryostat (Leica model 1850). Sections were taken at the rostral-caudal level of the orbital frontal cortex (approximately $4.2 \mathrm{~mm}$ anterior to bregma), the lateral septum (approximately $0.26 \mathrm{~mm}$ 
posterior to bregma), and the dorsal hippocampus (approximately $3.14 \mathrm{~mm}$ posterior to bregma). Sections were thaw-mounted onto poly L-lysine coated microscope slides and stored at $-80^{\circ} \mathrm{C}$.

In situ hybridization for $c$-fos mRNA was performed as described previously (Girotti et al., 2006). In situ hybridization, which exhibits excellent spatial resolution, provides better temporal resolution than assays for Fos protein levels (Kubik et al., 2007). A 35-S-UTP labeled cRNA probe was generated for $c$-fos mRNA using plasmids containing a fragment of $c$-fos $\mathrm{CDNA}$, which was kindly provided by Dr. Tom Curran (St. Jude Children's Research Hospital, Memphis, TN, USA). After completion of the in situ hybridization procedure, the sections were exposed to X-ray film (Kodak Bio-Max MR, Rochester, NY, USA) for approximately 2 weeks.

BRAIN REGIONS OF INTEREST AND AUTORADIOGRAPH DENSITOMETRY Since lesion, neuroimaging, and immediate early gene expression studies have suggested that there may be hippocampal subregion specialization in the processes of memory acquisition, consolidation, and retrieval (Lee and Kesner, 2004; Eldridge et al., 2005; Kubik et al., 2007; Poirier et al., 2008; VanElzakker et al., 2008), we examined $c$-fos mRNA in different hippocampal subregions, including the inner and outer blades of the dentate gyrus, and the CA1, CA2, CA3, and CA4 subregions of the dorsal hippocampus (Figure 2). Because the RAWM task is a motor task with an arousing component (water immersion), we examined $c$-fos mRNA in other brain regions that may reflect neural activity responsive to aspects of the test conditions other than activity associated exclusively with memory retrieval. Specifically, we quantified $c$-fos mRNA levels in forebrain regions commonly associated with stress and anxiety [septum, basolateral amygdala (BLA), and anterior cingulate cortex], emotional control (infralimbic, prelimbic, and ventral orbital subregions of the medial prefrontal cortex), operational learning (dorsomedial and dorsolateral striatum, DLS), olfactory processing (piriform cortex), and motor behavior (secondary motor cortex; Herman et al., 2003; Cui et al., 2004). The rostral-caudal determination of the regions of interest (ROI) for the BLA was based on
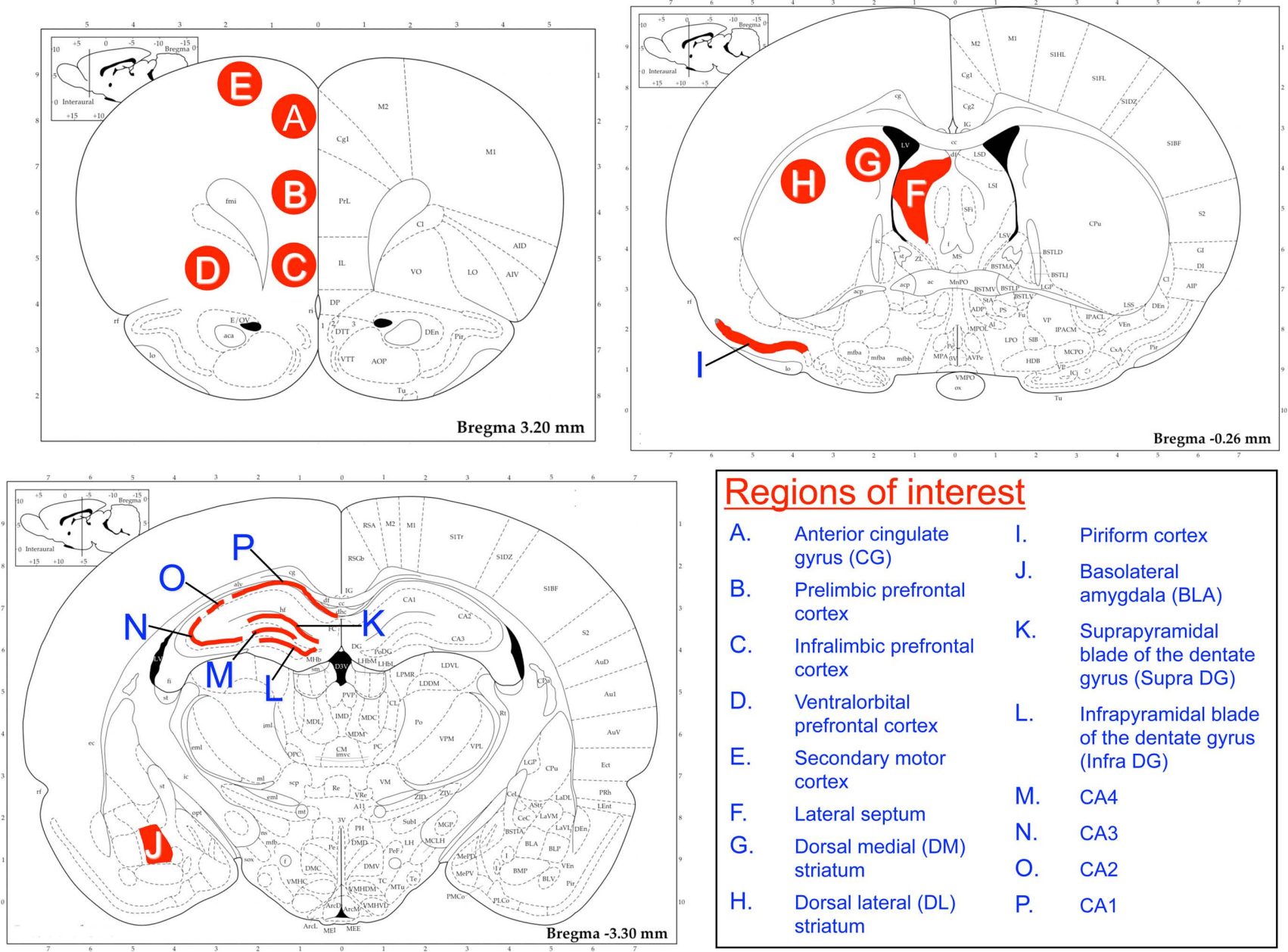

\section{Regions of interest}

A.

gyrus (CG)

B. Prelimbic prefrontal cortex

C. Infralimbic prefrontal cortex

D. Ventralorbital prefrontal cortex

E. Secondary motor cortex

F. Lateral septum

G. Dorsal medial (DM) striatum

H. Dorsal lateral (DL) striatum
I.

J.

Piriform cortex

Basolateral amygdala (BLA)

K. Suprapyramidal blade of the dentate gyrus (Supra DG)

L. Infrapyramidal blade of the dentate gyrus (Infra DG)

M. CA4

N. CA3

O. CA2

P. CA1
FIGURE 2 | Brain regions of interest for $\boldsymbol{c}$-fos mRNA analysis. Regions of interest (ROI) were selected based on their potential relationship to different aspects of the RAWM task, such as stress and anxiety (prefrontal regions, septum, and amygdala), swimming and sensory processing (secondary motor cortex and piriform cortex) and memory (hippocampal subregions, amygdala).
ROIs were overlaid on digitized autoradiographic images as shown. Lines illustrate an outline over the principle cell layer of the piriform cortex and hippocampal subregions; the septum and amygdala were outlined according to their shape in the Rat Brain Atlas (Paxinos and Watson, 1998), and circles were centered within the other ROIs. 
our previous finding of a strong relationship between $c$-fos mRNA levels and a behavioral response to stress in the BLA at this level (Weinberg et al., 2010). We used the Rat Brain Atlas (Paxinos and Watson, 1998) to visually guide ROI localization (Figure 2).

We determined the relative levels of specific $c$-fos mRNA hybridization from optical density measures of autoradiographs, as previously described (Campeau and Watson, 1997). Briefly, after the film was developed, the images were digitized by placing the film on a lightbox, and images of individual brain sections or ROIs were captured with a digital camera. Densitometry for each ROI was calculated using the freeware NIH Image computer application. For each ROI, four to six independent measures (separate sections and hemisphere measures) were taken for each brain and then averaged.

\section{STATISTICS}

Mixed-model, two-way ANOVAs (between-groups factor: training condition; within-groups factor: trial block) were used to analyze the arm entry errors in two trial blocks during the first (Trials 1-12) and second (Trials 13-18) phases of training on Day 1. A one-way ANOVA was used to analyze arm entry errors committed on the 24-h memory test in the RAWM, as well as for $c$-fos mRNA expression for each ROI and serum corticosterone levels. Alpha was set at 0.05 for all analyses. In cases where there was a significant omnibus F test, post hoc comparisons relative to the "Home Cage" group were tested for statistical significance using the Student-Newman-Keuls (SNK) test. Where indicated, additional exploratory post hoc comparisons used Student's $t$-test. Data in the graphs are presented as group mean \pm SEM.

\section{RESULTS}

\section{WATER MAZE ACQUISITION AND MEMORY PERFORMANCE}

All three groups of rats trained to find the escape platform (Standard, Pre-Training Stress Good, and Pre-Training Stress Bad Memory) exhibited learning of the platform location, as indicated by a significant effect of training block, $F(5,105)=18.07, p<0.001$, without a significant effect of training condition, $(p>0.05)$. There was no Training Condition $\times$ Training Block interaction $(p>0.05)$, indicating that the three groups learned the task at a statistically equivalent rate (Figure 3 ).

The three groups of trained rats exhibited equivalent performance on trials 13-18 (blocks 7-9), which was conducted $1 \mathrm{~h}$ after completion of the acquisition phase. Thus, there was a significant effect of training block, $F(2,42)=10.61, p<0.001$, reflecting additional improvement in performance across those six trials, and there was no Training Condition $\times$ Training Block interaction $(p>0.05)$, indicating that this improvement occurred at an equivalent rate across conditions.

In the 24-h memory test trial, the Standard train group exhibited excellent memory for the escape platform location, committing only $0.25( \pm 0.16)$ errors (Figure 3$)$. Rats in the Pre-Training Stress group exhibited a broad range of errors, from as few as 0 to as many as 6 errors in the 24-h memory performance of individual rats. This broad distribution of errors provided an opportunity to assess brain and behavior of rats into two subgroups: those that were perfect or near perfect in their memory performance [0 or 1 error, $n=8$; overall $0.5( \pm 0.19)$ errors $]$ and those that were impaired [ 2 or more errors; $n=8$; overall $3.12( \pm 0.39)$ errors]. A one-way
ANOVA of arm entry errors on the 24-h memory test trial for the three groups ( $n=8 /$ group) indicated a significant effect of group, $F(2,21)=34.43, p<0.001$. Post hoc tests indicated that the PreTraining Stress, Bad Memory group made significantly more arm entry errors than both the Standard group and the Pre-Training Stress, Good Memory group ( $p<0.001$, SNK), and that the Standard and the Pre-Training Stress, Good Memory groups were equivalent in their memory performance $(p>0.1, \mathrm{SNK})$.

\section{CORTICOSTERONE}

A one-way ANOVA revealed that plasma corticosterone levels at the time of sacrifice did not differ significantly among the conditions (expressed as $\mu \mathrm{g} / \mathrm{dL} \pm$ SEM: standard $=8.0 \pm 3.3$, Yoked $=7.4 \pm 1.6$, Pre-Training Stress, Good Memory $=4.0 \pm 1.2$, Pre-Training Stress, Bad Memory $=5.0 \pm 1.3$, Home Cage $=8.1 \pm 2.6 ; p>0.05)$.

\section{C-FOS mRNA IN THE HIPPOCAMPUS AFTER THE 24-H MEMORY TEST TRIAL}

The general pattern of between-group c-fos mRNA expression was similar across each of the hippocampal subregions (Figures 4 and 5). In each subregion except CA2, there was a significant increase of $c$-fos mRNA in the Standard group, relative to the Home Cage group [CA1: $F(4,35)=4.48, p=0.005$; CA3: $F(4,35)=3.00$, $p=0.03$; CA4: $F(4,35)=3.04, p=0.03$; DG supra: $F(4,35)=4.56$, $p=0.005$; DG infra: $F(4,35)=4.13, p=0.008)$. In all hippocampal subregions, $c$-fos mRNA expression in the Pre-Training Stress groups did not differ significantly from the Home Cage group. Only for CA1 both Pre-Training Stress groups exhibited significantly less expression of $c$-fos mRNA than the Standard trained group

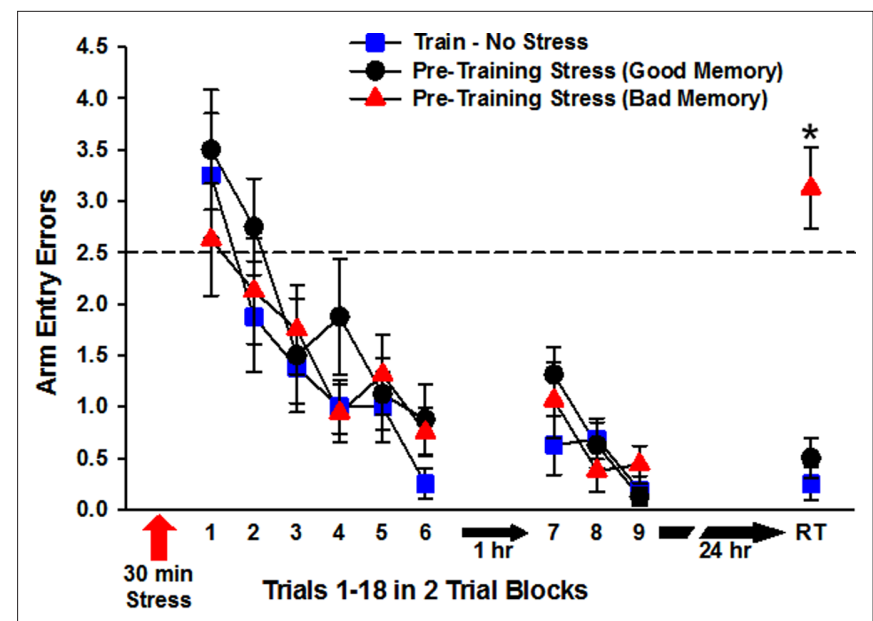

FIGURE 3 | Radial-arm water maze performance during the first and second phases of training on Day 1 and on the long-term (24 h) memory test trial (RT; retention trial). The three groups of rats performed at a statistically equivalent level during trials 1-12 (blocks 1-6) and trials 13-18 (blocks 7-9). Rats exposed to predator stress prior to training were split into good (Pre-Training Stress, Good) and bad (Pre-Training Stress, Bad) memory subgroups based on the number of errors they committed on the RT. As illustrated in the figure, the Pre-Training Stress, Bad group exhibited impaired $24 \mathrm{~h}$ spatial memory, relative to both of the other groups. The dashed line a 2.5 arm entry errors indicates chance level of performance (Diamond et al., 1999). ${ }^{*} p<0.001$ relative to the Standard Train and Pre-training Stress, Good memory groups (SNK post hoc test). 


\section{Hippocampal Formation $c$-fos mRNA}
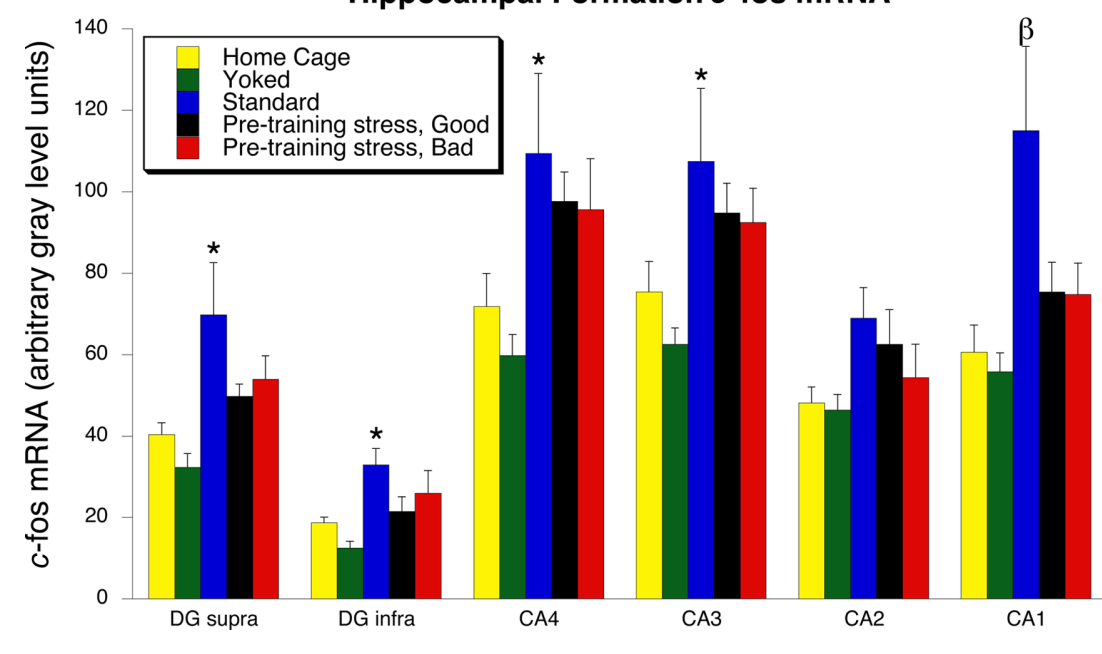

FIGURE 4 | c-fos mRNA expression in the dorsal hippocampus $30 \mathrm{~min}$ following the 24-h memory test trial. Standard training led to a significant increase in the expression of $c$-fos mRNA in every region of the dorsal hippocampus, except for CA2. An increased expression of $c$-fos mRNA was not found in the Pre-Training Stress Good and Bad Memory Groups in any subregion. The $\beta$ indicates that the expression of $c$-fos mRNA was significantly greater in CA1 than in the home cage and both Pre-Training Stress groups. ${ }^{*} p<0.05$ relative to the Home Cage group (SNK post hoc test). All hippocampal tissue was assayed in the same in situ films, thereby allowing for expression of the data in terms of arbitrary gray level units. $(p<0.05, \mathrm{SNK})$. The Good and Bad memory subgroups of PreTraining Stress rats exhibited statistically equivalent levels of $c$-fos mRNA expression across all of the hippocampal subregions. In addition, the Water Yoked group exhibited $c$-fos mRNA expression which was statistically equivalent to that of the Home Cage group across all hippocampal subregions ( $p>0.1, \mathrm{SNK})$.

\section{C-FOS mRNA IN NON-HIPPOCAMPAL STRUCTURES AFTER THE 24-H MEMORY TEST TRIAL}

Outside of the hippocampus, the only other brain ROI that demonstrated an overall significant effect of treatment condition on the expression of $c$-fos mRNA was the BLA (Figure 6). The Standard trained group displayed significantly greater expression of $c$-fos mRNA in the BLA than any other treatment condition $[F(3$, $29)=8.46, p<0.001$; SNK $p<0.05]$. An increase in $c$-fos mRNA, which was found in the BLA of the Standard trained group, was not found in the group of rats given pre-training stress.

Although there was not an overall significant effect of treatment condition on $c$-fos mRNA levels in the DLS, we performed a targeted post hoc exploratory analysis based on well-established findings of an increased involvement of the DLS in memory under conditions of reduced hippocampal functioning (White and McDonald, 2002; White and Salinas, 2003; Yin and Knowlton, 2004). We found a significant difference between $c$-fos $\mathrm{mRNA}$ levels in the DLS for the Stress Good Memory compared to Stress Bad Memory subgroups (one-tailed Student' $t$-test $(t(14)=1.9, p=0.04)$ (Figure 6).

\section{DISCUSSION}

We have studied the expression of $c$-fos mRNA associated with long-term spatial memory retrieval in rats administered water maze training under control conditions, and in rats which had been stressed before training began. Rats trained under control conditions exhibited excellent $24 \mathrm{~h}$ spatial memory which was associated with significantly increased levels of $c$-fos mRNA in the CA1, CA3, CA4, and dentate gyrus subdivisions of the dorsal hippocampus. In addition, long-term spatial memory retrieval was associated with increased $c$-fos mRNA in the BLA, which was unexpected, as this structure is known to be involved in emotional learning, but is not part of the essential circuitry underlying spatial learning and memory. When rats were administered predator stress prior to training, a significant increase in expression of $c$-fos mRNA in the hippocampus or BLA $24 \mathrm{~h}$ later was not present. However, despite this absence of $c$-fos mRNA expression in the hippocampus or BLA, half of all of the stressed rats exhibited intact long-term memory for the platform location. We propose that the stressed rats that exhibited intact memory deployed a non-spatial (non-hippocampal) strategy to encode the platform location. This putative stress-induced shift to a non-hippocampal brain memory system, such as the DLS, may have enabled a subset of the stressed rats to remember the location of the hidden platform, despite their exhibiting a lack of increased $c$-fos mRNA transcription in their hippocampus and BLA at the time of memory retrieval.

\section{HIPPOCAMPAL C-FOS MRNA AND LONG-TERM SPATIAL MEMORY RETRIEVAL}

Extensive work has shown that the hippocampus plays a pivotal role in the acquisition of a variety of spatial tasks (Kesner et al., 2004; Martin and Clark, 2007; Bird and Burgess, 2008) and that the dorsal, rather than ventral, hippocampus is important for acquiring spatial information (Bannerman et al., 1999, 2004; Pothuizen et al., 2004; Hunsaker and Kesner, 2008; Fanselow and Dong, 2010). Research over the past few decades has provided support for a role of the hippocampus in memory retrieval, as well (Riedel et al., 1999; Corcoran and Maren, 2001; Jezek et al., 2002; Szapiro et al., 2002; Micheau et al., 2004; Moscovitch et al., 2006; Nadel et al., 2007; Sutherland et al.,2010). Studies in humans have revealed that the hippocampus 


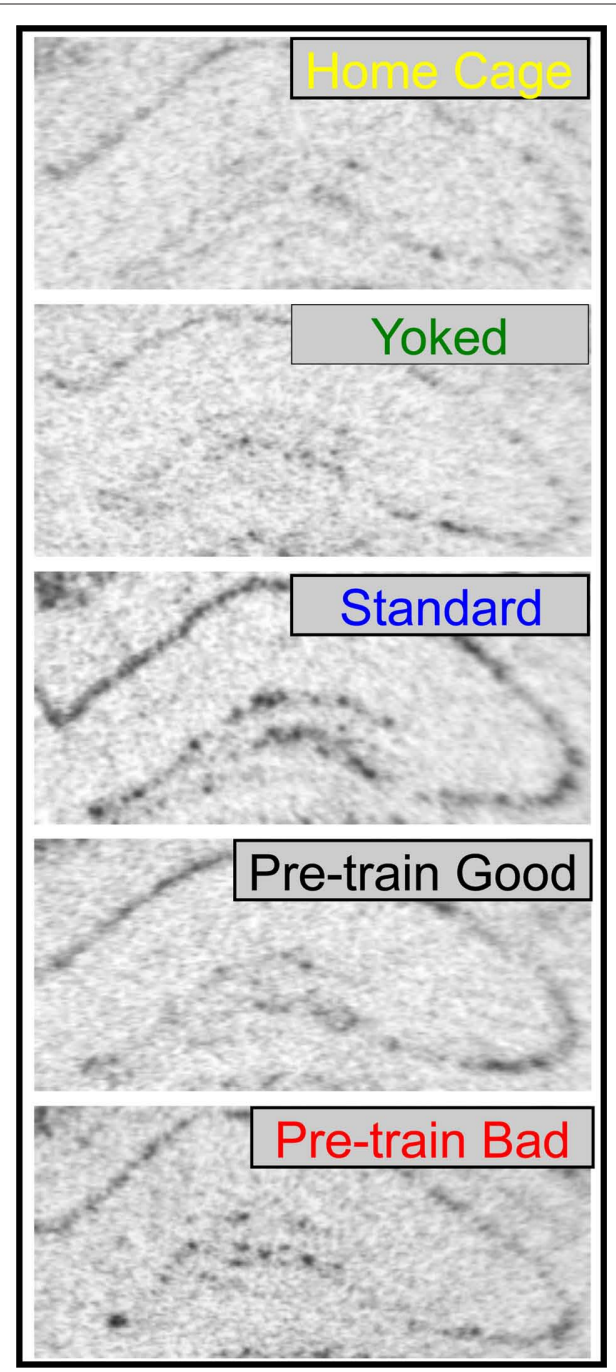

FIGURE 5 | Representative dorsal hippocampus autoradiograms (in situ hybridization) of $c$-fos mRNA following the 24-h memory test trial. Images from $x$-ray films were captured using a digital camera. The displayed images depict the dorsal hippocampus from one hemisphere of a coronal brain section.

can be activated by the acquisition, as well as retrieval, of semantic, episodic, and navigational memories (Dolan and Fletcher, 1999; Bosshardt et al., 2005; Rekkas and Constable, 2005; Moscovitch et al., 2006; Cabeza and St Jacques, 2007; Nadel et al., 2007; Spiers and Maguire, 2007a,b). Studies in animals have also reported an increase in hippocampal activity, including increased expression of immediate early genes, following memory retrieval (Bontempi et al., 1999; Szapiro et al., 2002; Mayer et al., 2010; Wiltgen et al., 2010). The findings reported here are consistent with and extend those earlier findings to show that water maze spatial memory retrieval by rats occurring $24 \mathrm{~h}$ after training resulted in increased hippocampal immediate early gene ( $c$-fos) expression.

It is important to emphasize that the increased $c$-fos mRNA expression in the hippocampus (and BLA) was generated by spatial memory retrieval, itself, and was not produced merely as a consequence of the sensorimotor components of water exposure, per se; rats that were given an equivalent amount of water maze exposure, but not trained to learn the location of a hidden platform (Water Yoked group), did not express increased $c$-fos mRNA in any examined brain region. These findings are consistent with recent work from our group which has detected a rapid and dorsal CA1-specific phosphorylation of calcium calmodulin kinase II (CaMKII) in response to spatial learning, but not in a water yoked group (Zoladz et al., 2011). Overall, our findings from animals trained under control conditions reveal a clear association between increased molecular plasticity in the hippocampus, a structure wellknown for its contribution to the acquisition of spatial information, and the retrieval of a long-term ( $24 \mathrm{~h})$ spatial memory.

The training-induced increase in $c$-fos mRNA expression was almost exclusively selective to the hippocampus, as the only other brain region in which non-stressed rats given standard training exhibited an increase was the BLA (discussed below). How the retrieval-induced increase in hippocampal activity is specifically involved in long-term memory processes is not well understood. Given that $c$-fos gene expression is an intracellular response tightly coupled with neuroplasticity (Herdegen and Leah, 1998; Kubik et al., 2007), the increased transcription of hippocampal c-fos mRNA associated with memory retrieval could be involved in retrieval-induced reconsolidation processes which require renewed activation of neuroplasticity (Dudai, 2002; Tronson and Taylor, 2007).

\section{C-FOS mRNA, STRESS, HIPPOCAMPAL, AND NON-HIPPOCAMPAL MEMORY PROCESSING}

In addition to studying $c$-fos mRNA and memory under standard training conditions, we included a group that was administered pre-training predator stress, followed by measurement of brain c-fos mRNA expression $30 \mathrm{~min}$ after the 24-h memory test trial. We found that this group lacked a significant increase in hippocampal c-fos mRNA expression following the 24-h memory test trial (Figure 4). More specifically, the stress-induced suppression of $c$-fos mRNA expression was most profound in CA1, which exhibited a complete suppression of the training effect (Figure 4). This difference between CA1 and other hippocampal regions is consistent with lesion and fMRI studies suggesting that CA3 and the dentate gyrus play a role in acquisition, while CA1 is important for hippocampus-dependent learning and memory retrieval (Lee and Kesner, 2004; Eldridge et al., 2005). This finding is also consistent with the extensive evidence that CA1, more than other hippocampal regions, has been found across paradigms and laboratories to exhibit a potent suppression of synaptic plasticity (LTP and primed burst potentiation) in response to stress (Kim and Diamond, 2002; Diamond et al., 2007; Tsoory et al., 2008; Joëls et al., 2009) Thus, our finding that $c$-fos mRNA expression in CA1 was highly sensitive to increase in response to spatial learning and to be completely suppressed in response to stress parallels behavioral findings demonstrating an impairment of hippocampus-dependent memory in response to stress (Bremner et al., 1995; Joseph, 1999; Kim and Diamond, 2002; Diamond et al., 2007; Sandi and Pinelo-Nava, 2007; Schwabe et al., 2009; Schwabe and Wolf, 2010; Zoladz et al., 2010).

The more general finding of a global suppression of $c$-fos mRNA transcription in the hippocampus of the Pre-Training Stress group is consistent with previous work from our laboratory in which 


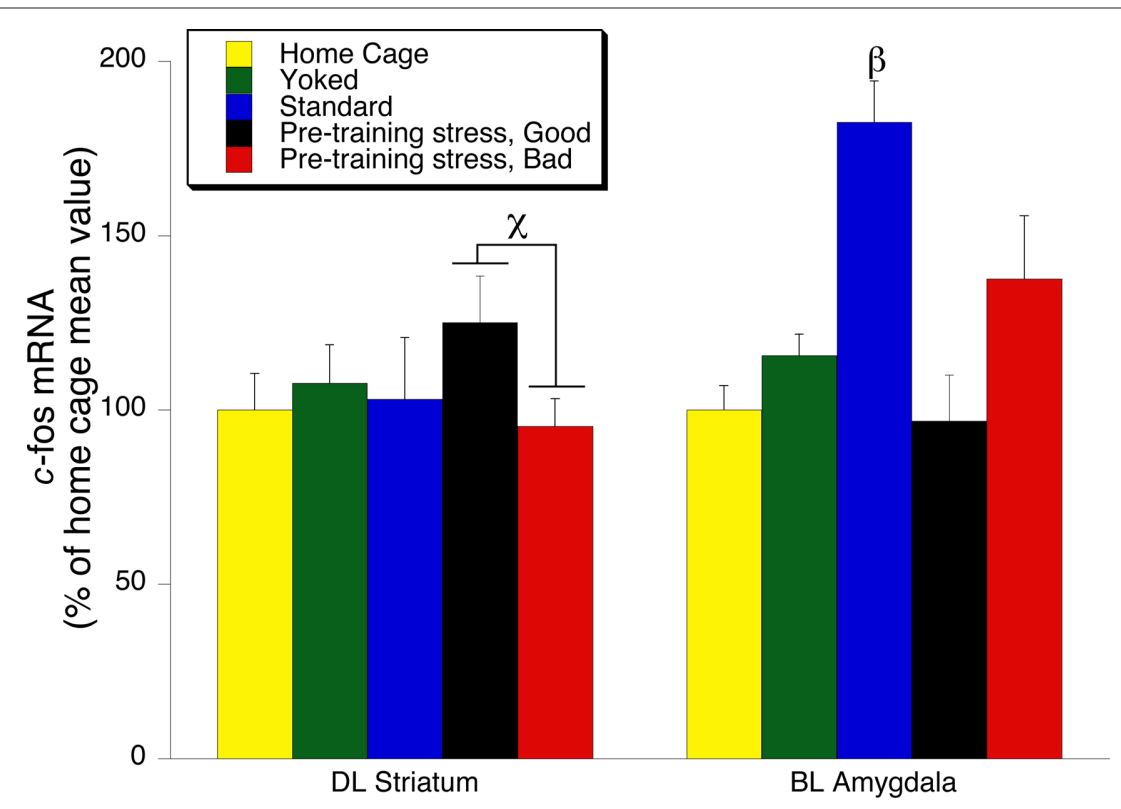

FIGURE 6 | $c$-fos mRNA expression in the Dorsolateral (DL) striatum, and Basolateral (BL) amygdala 30 min following the 24-h memory test trial. The left side of the graph illustrates a significant increase in the expression of $c$-fos mRNA in the Pre-Training Stress Good compared to the Pre-Training Stress Bad Memory Groups ( $\chi$ indicates $p<0.05$, one-tailed $t$-test). The right side of the graph illustrates a significant increase in the expression of $c$-fos
mRNA in the Basolateral $(B L)$ amygdala in the Standard trained group compared to all other groups ( $p<0.05$, SNK post hoc test). The data from the $\mathrm{DL}$ and $\mathrm{BLA}$ and were obtained from tissue samples which were assayed in different in situ films. Therefore, the data were normalized to responses within each region, and expressed as a percent of the home cage response for each brain structure. pre-training exposure of rats to $30 \mathrm{~min}$ of predator stress impaired 24 h water maze memory (Park et al., 2008), and blocked molecular processes known to be involved in memory consolidation, including activation of NCAMs (Sandi et al., 2005), phosphorylation of calcium calmodulin kinase II (CaMKII; Zoladz et al., 2011), and the traininginduced increase in the density of dendritic spines on CA1 neurons (Diamond et al., 2006). Overall, the absence of a significant increase in $c$-fos mRNA expression in the hippocampus of rats administered pre-training stress in the current work is consistent with the extensive literature demonstrating that stress can impair hippocampal function (Lupien and Lepage, 2001; McEwen, 2001; Kim and Diamond, 2002; Sandi, 2004; Joëls et al., 2006; Packard, 2009).

The finding of excellent $24 \mathrm{~h}$ memory performance in conjunction with the increased $c$-fos mRNA levels in the hippocampus in the Standard (non-stress) group is consistent with the well-established role of the hippocampus in spatial learning and memory. Conversely, the absence of changes in $c$-fos mRNA induction in the hippocampus of the Pre-Training Stress Good and Bad memory groups, relative to the Home Cage control group, supports the hypothesis that the hippocampus did not participate in the retrieval of the memory of the platform location for this group. It was therefore an unexpected finding that so many rats in the stress group exhibited intact $24 \mathrm{~h}$ memory for the hidden platform; half of all stressed rats exhibited intact $24 \mathrm{~h}$ memory ( 0 or 1 error), while the other half exhibited bad memory ( $\geq 2$ errors). It is important to note that the rats in the Pre-Training Stress Good versus Bad memory groups learned the water maze task at an equivalent rate, and both subgroups performed as well on the short-term memory trials as the non-stressed Control (Standard) trained group
(Figure 3). Therefore, the equivalent levels of performance of all three groups on Day 1 of training indicates that any adverse effects of pre-training stress on long-term memory could not be attributed to a disruption of acquisition or short-term memory processes, or to trivial explanations, such as a lack of attention to the task or to a lack of motivation to escape the water.

Why there was a broad distribution in long-term memory performance by rats in the Pre-Training Stress group cannot be determined with any certainty, as all of the animals in this group were administered the same stress and behavioral training parameters. In previous work we found that, as a group, rats that were stressed before training were impaired in their $24 \mathrm{~h}$ memory performance (Park et al., 2008). In that study, $75 \%$ of all rats given pre-training stress exhibited impaired $24 \mathrm{~h}$ memory performance, while in the current study only $50 \%$ of the stressed rats exhibited impaired memory performance. It is possible that subtle differences in the training environments, such as the local intensity of cues and lighting, across the two studies may have enabled the pre-training stress rats in the current study to utilize isolated cues to remember the platform location more effectively than in the previous work.

Although it is a matter of speculation as to why half of all stressed rats exhibited intact $24 \mathrm{~h}$ memory, the finding is not without precedence. Other work on stress, as well as hippocampal lesion studies, have demonstrated that under conditions of reduced hippocampal functioning, a subset of rats appear to switch their learning strategy to deploy a non-hippocampal-based brain memory system to remember a goal location (McDonald and White, 1993, 1994; White and Salinas, 2003; Packard, 2009; White, 2009). One such non-hippocampal memory system involves the use of a habit or 
motor, form of learning. In this case, if an animal performs the same motor response on each training trial, e.g., turn right out of the start location to find the goal, it has the opportunity to use a non-hippocampal memory system to remember its motor response to find the platform, rather than to remember the location of the platform (Packard, 2009).

Extensive research has shown that when rats are trained to remember repetitive habit or motor-based associations they deploy their caudate/striatum (habit-based) memory system to locate a goal (Packard and McGaugh, 1996; Packard and Teather, 1997; Packard, 1999). However, it was not possible for the stressed rats in the current study to have used a habit-based memory system to remember the location of the hidden escape platform since the relation between the start and goal arm locations was randomized across trials. Instead, the stressed rats that exhibited intact $24 \mathrm{~h}$ memory of the hidden platform needed to remember where the platform was located, rather than to remember their motor responses during training.

A better explanation for how a subset of the stressed rats exhibited intact memory is based on work demonstrating that under certain conditions rats can use a non-hippocampal brain memory system to remember a goal location. That is, rats normally use their hippocampus to bind together the multiple cues in an environment to generate a higher order representation of the spatial location of a goal (O'Keefe and Nadel, 1978; Fanselow, 2000; Rudy, 2009). However, in response to hippocampal damage or stress, a subset of rats appear to shift their mnemonic strategy from generating a cognitive/spatial representation to remembering discrete, isolated cues associated with the goal location (McDonald and White, 1994; Devan and White, 1999). In one example of this phenomenon which is highly relevant to the current findings, Kim et al. (2001) used methodology and reported findings which closely paralleled those of the current work. These investigators studied the effects of pretraining stress (restraint and shock) on $24 \mathrm{~h}$ water maze memory. They found that the stressed rats exhibited a greater tendency than control rats to use a non-hippocampal (cue-based) strategy to retrieve the 24-h memory of the hidden platform location. Just as we found an absence of hippocampal $c$-fos transcription in stressed rats, Kim et al. (2001) showed impaired hippocampal function, as measured by a suppression of LTP, in their stressed rats. Their findings and ours support the hypothesis that when rats are trained to find a goal under stress conditions, a substantial subset of the rats learn and then retrieve that information through the activation of non-hippocampal brain structure(s). This shifting of strategy from the use of a hippocampal (cognitive map) to a non-hippocampal (isolated cue) representation of the environment may also be influenced by stress-gender interactions, as evidence by a greater effect of stress on hippocampus-dependent memory on males than on females (see Park et al., 2008 for relevant findings and discussion of stress-gender interactions).

Studies utilizing pharmacological and lesion methodology have provided insight into how stress can induce a shift from hippocampal to non-hippocampal memory consolidation and retrieval strategies. In one example, Schwabe et al. (2010a) demonstrated that stress or corticosterone injection induced rats to switch from their normal cognitive/spatial strategy to use a discrete cue to learn and then remember a goal location. Moreover, they demonstrated that the stress effects were mediated by the mineralocorticoid receptor (MR), as an MR antagonist blocked the stress- and corticosteroneinduced shift to the discrete cue learning strategy. In lesion and inactivation studies, McDonald, White, and coworkers (McDonald and White, 1994; White and Salinas, 2003; White, 2009) have shown that rats with hippocampal damage tend to use isolated cues to identify the location of a goal. Moreover, these investigators have shown that the DLS is the critical structure which enables rats to shift from a cognitive to cue-based memory strategy.

In the current work, the maze training room contained distinct visual cues, such as indirect lighting in one corner of the room and a door with a window, which could have served as the isolated cues that the stressed rats associated with the hidden platform. In theory, although all of the stressed rats had impaired hippocampal functioning at the time of water maze training, a subset of the stressed rats exhibited flexibility which enabled them to utilize a non-hippocampal memory system to learn, and then remember, the platform location. We would further speculate, based on the pharmacological and lesion studies discussed above, that predator stress occurring prior to training, and its presumed concomitant increase in CORT levels (Diamond et al., 1999; Woodson et al., 2003; Sandi et al., 2005), would have increased activation of MR receptors, thereby increasing the likelihood that the stressed rats would depend on their DLS, rather than their hippocampus, to use isolated and distinct room cue(s) to remember the platform location.

There is empirical support for our suggestion that the stressed rats with intact memory used their DLS to retrieve the memory of the platform location. We found that pre-training stress rats with good $24 \mathrm{~h}$ memory exhibited greater $c$-fos mRNA expression in the DLS than pre-training stress rats with bad $24 \mathrm{~h}$ memory (Figure 6). Therefore, the $c$-fos mRNA findings reported here are consistent with the literature indicating that the DLS can serve as an alternative brain memory system which enabled a subset of pre-training stress animals to remember the location of the hidden platform. That the $c$-fos signal in the DLS was relatively weak is consistent with other work demonstrating that $c$-fos levels associated with memory retrieval are considerably less than those found in response to acquisition in a spatial learning task (Mayer et al., 2010). Therefore, the current work, in conjunction with the broader stress-memory literature, indicates that the DLS should be a target for analysis of the differential expression of synaptic plasticity in stressed animals which exhibit intact versus impaired memory.

\section{BASOLATERAL AMYGDALA, C-FOS mRNA, SPATIAL LEARNING, STRESS, AND MEMORY}

The only brain region other than the hippocampus to express a significant increase in $c$-fos $\mathrm{mRNA}$ following $24 \mathrm{~h}$ memory retrieval under the control (non-stress) condition was the BLA (Figure 6). This is an intriguing finding given that the BLA is not a necessary component of spatial learning and memory neural circuitry (Roozendaal et al., 2003; Kim et al., 2005). Nevertheless, although the BLA is not necessary for spatial learning and memory to take place, inactivation of or damage to the BLA can affect aspects of the performance of rats in spatial learning tasks (White and McDonald, 1993; Gaskin and White, 2006). Moreover, studies 
investigating molecular plasticity induced by learning and memory have provided evidence of BLA involvement in hippocampusdependent tasks. For example, water maze training with cold versus warm water maze training has been shown to enhance long-term memory retention (Sandi et al., 1997; Kogan and Richter-Levin, 2010), as well as to increase BLA phosphorylation of extracellular regulated kinase 2 (Akirav et al., 2001), which is critically involved in memory consolidation and synaptic plasticity (Impey et al., 1999). Complementary findings by Conejo et al. (2010) demonstrated that there is an increase in cytochrome oxidase activity (a marker for localized increases in oxidative metabolism) in the BLA within $24 \mathrm{~h}$ after initiation of water maze training. Thus, our findings are consistent with the broader literature indicating that while the integrity of the BLA is not necessary for the performance of the learned response, mechanisms of plasticity are activated in the BLA which may influence the expression of long-term spatial memory retrieval.

Insight into how the BLA may be involved in spatial learning and memory has been provided in work by Galliot et al. (2010) in their multi-level analysis of how the BLA influences spatial learning. These authors reported that the inclusion of predator odor in the water maze training environment enhanced spatial learning and increased Fos immunoreactivity levels in the hippocampus. In this work, lesioning the BLA did not impair water maze learning, per se, but the odor-mediated influence on memory and Fos were both blocked by damage to the BLA. Taken together, these findings indicate that the increased $c$-fos mRNA expression in the BLA reported in the current study is not necessary for spatial learning and memory, per se. Instead, we would interpret the increased $c$-fos mRNA in the BLA evoked by spatial memory retrieval to reflect the contribution of the BLA to the emotional and/or motivational component of spatial learning and memory (Bischoff-Grethe et al., 2009).

It is important to note that the increase in $c$-fos mRNA in the BLA observed under no stress conditions was not present in the group which was administered pre-training stress. Thus, whereas increased BLA activation has been reported in studies of animals with intact water maze memory, the finding of suppressed BLA activity in animals which were stressed in conjunction with water maze training has not been reported in any previous work. We hypothesize that BLA activation under control conditions serves as a motivational and reinforcing influence in response to intact hippocampal-based memory reactivation. However, when hippocampal-based memory reactivation was suppressed by pretraining stress, the BLA reinforcement component was suppressed,

\section{REFERENCES}

Akirav, I., Sandi, C., and Richter-Levin, G. (2001). Differential activation of hippocampus and amygdala following spatial learning under stress. Eur. J. Neurosci. 14, 719-725.

Bannerman, D. M., Rawlins, J. N., McHugh, S. B., Deacon, R. M., Yee, B. K., Bast, T., Zhang, W. N., Pothuizen, H. H., and Feldon, J. (2004). Regional dissociations within the hippocampus-memory and anxiety. Neurosci. Biobehav. Rev. 28, 273-283.

Bannerman, D. M., Yee, B. K., Good, M. A., Heupel, M. J., Iversen, S. D., and Rawlins, J. N. (1999). Double dissociation of function within the hippocampus: a comparison of dorsal, ventral, and complete hippocampal cytotoxic lesions. Behav. Neurosci. 113, 1170-1188.

Bekinschtein, P., Cammarota, M., Izquierdo, I., and Medina, J.H. (2008).

as well. This would suggest that BLA-based reinforcement of spatial memory must occur in conjunction with intact hippocampal-based memory retrieval.

Overall, our findings of $c$-fos mRNA in the BLA provide a novel perspective on how this brain structure may be involved in aspects of spatial memory processing. First, we have found that the BLA is activated in response to spatial memory reactivation under control conditions. Although the BLA is not necessary for spatial memory to occur, we have suggested that its activation under control conditions provides reinforcement for the memory, potentially strengthening its durability. Second, rats that were stressed before training, and thereby lacked an increase in $c$-fos mRNA in the hippocampus, failed to mount a significant increase in $c$-fos mRNA in the BLA. Thus, the memory reinforcing aspects of BLA activity may be linked to processes involved in successful memory reactivation by the hippocampus.

\section{CONCLUSION}

We have shown that long-term (24 h) spatial memory retrieval results in increased $c$-fos $\mathrm{mRNA}$ expression in the dorsal hippocampus and in the BLA of rats given water maze training under the control (non-stress) condition. We have also shown that pre-training predator stress, independent of its effects on $24 \mathrm{~h}$ memory performance, prevented the training-induced increase of $c$-fos mRNA expression in the dorsal hippocampus and BLA. Rats exposed to pre-training predator stress exhibited a broad range of errors in their $24 \mathrm{~h}$ memory test trial, with half of the stressed rats exhibiting intact memory ( 0 or 1 error) and the other half had impaired memory (2-6 errors). Since pre-training stress rats that demonstrated good $24 \mathrm{~h}$ memory also showed an increase in $c$-fos mRNA expression within the DLS, these rats may have used their DLS to deploy a non-spatial (e.g., cue-based) strategy to acquire, as well as to retrieve, the memory of the hidden platform location. Future work is needed, however, to corroborate this speculation. Overall, our findings provide clear evidence for hippocampal and BLA involvement in long-term $(24 \mathrm{~h})$ spatial memory retrieval. They also indicate that pre-training stress suppressed hippocampal function, which resulted in impaired long-term memory only for those rats that did not shift to a non-hippocampal form of memory processing.

\section{ACKNOWLEDGMENTS}

This research was supported by Research Career Scientist and Merit Review Awards from the Department of Veterans Affairs to David Diamond and NIH grant MH75968 to Robert Spencer.

BDNF and memory formation and storage. Neuroscientist 14, 147-156.

Bird, C. M., and Burgess, N. (2008). The hippocampus and memory: insights from spatial processing. Nat. Rev. Neurosci. 9, 182-194.

Bisaz, R., Conboy, L., and Sandi, C. (2009) Learning under stress: a role for the neural cell adhesion molecule NCAM. Neurobiol. Learn. Mem. 91, 333-342.

Bischoff-Grethe, A., Hazeltine, E., Bergren, L., Ivry, R. B., and Grafton, S. T. (2009).
The influence of feedback valence in associative learning. Neuroimage 44, 243-251.

Bontempi, B., Laurent-Demir, C., Destrade, C., and Jaffard, R. (1999). Time-dependent reorganization of brain circuitry underlying longterm memory storage. Nature 400, 671-675.

Bosshardt, S., Degonda, N., Schmidt, C. F., Boesiger, P., Nitsch, R. M., Hock, C., and Henke, K. (2005). Onemonth of human 
memory consolidation enhances retrieval-related hippocampal activity. Hippocampus 15, 1026-1040.

Bremner, J. D., Krystal, J. H., Southwick, S. M., and Charney, D. S. (1995). Functional neuroanatomical correlates of the effects of stress on memory. J. Trauma Stress 8, 527-553.

Cabeza, R., and St Jacques, P. (2007). Functional neuroimaging of autobiographical memory. Trends Cogn. Sci. (Regul. Ed.) 11, 219-227.

Campeau, S., and Watson, S. J. (1997). Neuroendocrine and behavioral responses and brain pattern of c-fos induction associated with audiogenic stress. J. Neuroendocrinol. 9, 577-588.

Colombo, P. J., Brightwell, J. J., and Countryman, R. A. (2003). Cognitive strategy-specific increases in phosphorylated cAMP response elementbinding protein and c-Fos in the hippocampus and dorsal striatum. J. Neurosci. 23, 3547-3554.

Conboy, L., Tanrikut, C., Zoladz, P. R., Campbell, A. M., Park, C. R., Gabriel, C., Mocaer,E., Sandi, C., and Diamond, D. M. (2009). The antidepressant agomelatine blocks the adverse effects of stress on memory and enables spatial learning to rapidly increase neural cell adhesion molecule (NCAM) expression in the hippocampus of rats. Int. J. Neuropsychopharmacol. 12, 329-341.

Conejo, N. M., Gonzalez-Pardo, H., Gonzalez-Lima, F., and Arias, J. L. (2010). Spatial learning of the water maze: progression of brain circuits mapped with cytochrome oxidase histochemistry. Neurobiol. Learn. Mem. 93, 362-371.

Corcoran, K. A., and Maren, S. (2001). Hippocampal inactivation disrupts contextual retrieval of fear memory after extinction. J. Neurosci. 21, 1720-1726.

Cui, Y., Yan, Z., Hou, S., and Chang, Z. (2004). Effect of radix Rehmanniae preparata on the expression of c-fos and NGF in hippocampi and learning and memory in rats with damaged thalamic arcuate nucleus. Zhong Yao Cai 27, 589-592.

Devan, B. D., and White, N. M. (1999). Parallel information processing in the dorsal striatum: relation to hippocampal function. J. Neurosci. 19, 2789-2798.

Diamond, D. M., Campbell,A. M., Park, C. R., Halonen, J., and Zoladz, P. R. (2007). The temporal dynamics model of emotional memory processing: a synthesis on the neurobiological basis of stress-induced amnesia, flashbulb and traumatic memories, and the YerkesDodson law. Neural Plast. 60803.

Diamond, D. M., Campbell, A. M., Park, C. R., Woodson, J. C., Conrad, C. D.,
Bachstetter, A. D., and Mervis, R. F. (2006). Influence of predator stress on the consolidation versus retrieval of long-term spatial memory and hippocampal spinogenesis. Hippocampus 16, 571-576

Diamond, D. M., Park, C. R., Heman, K. L., and Rose, G. M. (1999). Exposing rats to a predator impairs spatial working memory in the radial arm water maze. Hippocampus 9, 542-552.

Dolan, R. J., and Fletcher, P. F. (1999). Encoding and retrieval in human medial temporal lobes: an empirical investigation using functional magnetic resonance imaging (fMRI). Hippocampus 9, 25-34.

Dudai, Y. (2002). Molecular bases of long-term memories: a question of persistence. Curr. Opin. Neurobiol. 12, 211-216.

Eldridge, L. L., Engel, S. A., Zeineh, M. M., Bookheimer, S. Y., and Knowlton, B. J. (2005).A dissociation of encoding and retrieval processes in the human hippocampus. J. Neurosci. 25, 3280-3286.

Fanselow, M. S. (2000). Contextual fear, gestalt memories, and the hippocampus. Behav. Brain Res. 110, 73-81.

Fanselow, M. S., and Dong, H. W. (2010). Are the dorsal and ventral hippocampus functionally distinct structures? Neuron 65, 7-19.

Frankland, P. W., Bontempi, B., Talton, L. E., Kaczmarek, L., and Silva, A. J. (2004). The involvement of the anterior cingulate cortex in remote contextual fear memory. Science 304, 881-883.

Gall, C. M., Hess, U. S., and Lynch, G. (1998). Mapping brain networks engaged by, and changed by, learning. Neurobiol. Learn. Mem. 70, 14-36.

Galliot, E., Levaillant, M., Beard, E., Millot, J. L., and Pourie, G. (2010). Enhancement of spatial learning by predator odor in mice: involvement of amygdala and hippocampus. Neurobiol. Learn. Mem. 93, 196-202.

Gaskin, S., and White, N. M. (2006). Cooperation and competition between the dorsal hippocampus and lateral amygdala in spatial discrimination learning. Hippocampus 16, 577-585.

Ginsberg, A. B., Campeau, S., Day, H. E., and Spencer, R. L. (2003). Acute glucocorticoid pretreatment suppresses stress-induced hypothalamicpituitary-adrenal axis hormone secretion and expression of corticotropin-releasing hormone hnRNA but does not affect c-fos mRNA or fos protein expression in the paraventricular nucleus of the hypothalamus. J. Neuroendocrinol. 15, 1075-1083.

Girotti, M., Pace, T. W., Gaylord, R. I., Rubin, B. A., Herman, J. P., and
Spencer, R. L. (2006). Habituation to repeated restraint stress is associated with lack of stress-induced c-fos expression in primary sensory processing areas of the rat brain. Neuroscience 138, 1067-1081.

Greenberg, M. E., Ziff, E. B., and Greene, L. A. (1986). Stimulation of neuronal acetylcholine receptors induces rapid gene transcription. Science 234, 80-83. Guzowski, J. F., and McGaugh, J. L. (1997) Antisense oligodeoxynucleotidemediated disruption of hippocampal cAMP response element binding protein levels impairs consolidation of memory for water maze training. Proc. Natl. Acad. Sci. U.S.A. 94, 2693-2698.

Guzowski, J. F., Setlow, B., Wagner, E. K., and McGaugh, J. L. (2001). Experience-dependent gene expression in the rat hippocampus after spatial learning: a comparison of the immediate-early genes Arc, c-fos, and zif268. J. Neurosci. 21, 5089-5098.

Hall, J., Thomas, K. L., and Everitt, B. J. (2001). Cellular imaging of zif268 expression in the hippocampus and amygdala during contextual and cued fear memory retrieval: selective activation of hippocampal CA1 neurons during the recall of contextual memories. J. Neurosci. 21, 2186-2193.

He, J., Yamada, K., and Nabeshima, T. (2002). A role of Fos expression in the CA3 region of the hippocampus in spatial memory formation in rats. Neuropsychopharmacology 26, 259-268.

Herdegen, T., and Leah, J. D. (1998). Inducible and constitutive transcription factors in the mammalian nervous system: control of gene expression by Jun, Fos and Krox, and CREB/ATF proteins. Brain Res. Brain Res. Rev. 28, 370-490.

Herman, J. P., Figueiredo, H., Mueller, N. K., Ulrich-Lai, Y., Ostrander, M. M., Choi, D. C., and Cullinan, W. E. (2003). Central mechanisms of stress integration: hierarchical circuitry controlling hypothalamo-pituitaryadrenocortical responsiveness. Front. Neuroendocrinol. 24, 151-180.

Hunsaker, M. R., and Kesner, R. P. (2008). Dissociations across the dorsal-ventral axis of CA3 and CA1 for encoding and retrieval of contextual and auditorycued fear. Neurobiol. Learn. Mem. 89, 61-69.

Impey, S., Obrietan, K., and Storm, D. R. (1999). Making new connections: role of ERK/MAP kinase signaling in neuronal plasticity. Neuron 23, 11-14.

Jezek, K., Wesierska, M., and Fenton, A. A. (2002). Hippocampus-dependent retrieval and hippocampusindependent extinction of place avoidance navigation, and stress- induced out-of-context activation of a memory revealed by reversible lesion experiments in rats. Physiol. Res. 51(Suppl. 1), S35-S47.

Joëls, M., Krugers, H. J., Lucassen, P. J., and Karst, H. (2009). Corticosteroid effects on cellular physiology of limbic cells. Brain Res. 1293, 91-100.

Joëls, M., Pu, Z., Wiegert, O., Oitzl, M. S., and Krugers, H. J. (2006). Learning under stress: how does it work? Trends Cogn. Sci. (Regul. Ed.) 10, 152-158.

Joseph, R. (1999). The neurology of traumatic "dissociative" amnesia: commentary and literature review. Child Abuse Negl. 23, 715-727.

Kesner, R. P., Lee, I., and Gilbert, P. (2004) A behavioral assessment of hippocampal function based on a subregional analysis. Rev. Neurosci. 15, 333-351.

Kim, J. J., and Diamond, D. M. (2002). The stressed hippocampus, synaptic plasticity and lost memories. Nat. Rev. Neurosci. 3, 453-462.

Kim, J. J., Koo, J. W., Lee, H. J., and Han, J. S. (2005). Amygdalar inactivation blocks stress-induced impairments in hippocampal long-term potentiation and spatial memory. J. Neurosci. 25, 1532-1539.

Kim, J. J., Lee, H. J., Han, J. S., and Packard, M. G. (2001). Amygdala is critical for stress-induced modulation of hippocampal long-term potentiation and learning. J. Neurosci. 21, 5222-5228.

Kogan, I., and Richter-Levin, G. (2010). Emotional memory formation under lower versus higher stress conditions. Front. Behav. Neurosci. 4:183. doi: 10.3389/fnbeh.2010.00183

Kovacs, K. J. (2008). Measurement of immediate-early gene activationc-fos and beyond. J. Neuroendocrinol. 20, 665-672.

Kubik, S., Miyashita, T., and Guzowski, J.F. (2007). Using immediate-early genes to map hippocampal subregional functions. Learn. Mem. 14, 758-770.

Lee, I., and Kesner, R. P. (2004). Encoding versus retrieval of spatial memory: double dissociation between the dentate gyrus and the perforant path inputs into CA3 in the dorsal hippocampus. Hippocampus 14, 66-76.

Lupien, S. J., and Lepage, M. (2001). Stress, memory, and the hippocampus: can't live with it, can't live without it. Behav. Brain Res. 127, 137-158.

Martin, S. J., and Clark, R. E. (2007). The rodent hippocampus and spatial memory: from synapses to systems. Cell. Mol. Life Sci. 64, 401-431.

Mayer, U., Watanabe, S., and Bischof, H. J. (2010). Hippocampal activation of immediate early genes Zenk and c-Fos in zebra finches (Taeniopygia guttata) during learning and recall of a spatial 
memory task. Neurobiol. Learn. Mem. 93, 322-329.

McDonald, R. J., and White, N. M. (1993). A triple dissociation of memory systems: hippocampus, amygdala, and dorsal striatum. Behav. Neurosci. 107, 3-22.

McDonald, R. J., and White, N. M. (1994). Parallel information processing in the water maze: evidence for independent memory systems involving dorsal striatum and hippocampus. Behav. Neural Biol. 61, 260-270.

McEwen, B. S. (2001). Plasticity of the hippocampus: adaptation to chronic stress and allostatic load. Ann. N. Y. Acad. Sci. 933, 265-277.

Mesches, M. H., Fleshner, M., Heman, K. L., Rose, G. M., and Diamond, D. M. (1999). Exposing rats to a predator blocks primed burst potentiation in the hippocampus in vitro. J. Neurosci. 19, RC18.

Micheau, J., Riedel, G., Roloff, E. L., Inglis, J., and Morris, R. G. (2004). Reversible hippocampal inactivation partially dissociates how and where to search in the water maze. Behav. Neurosci. 118, 1022-1032.

Miyamoto, E. (2006). Molecular mechanism of neuronal plasticity: induction and maintenance of long-term potentiation in the hippocampus. $J$. Pharmacol. Sci. 100, 433-442.

Morris, R. G., Anderson, E., Lynch, G. S., and Baudry, M. (1986). Selective impairment of learning and blockade of long-term potentiation by an N-methyl-D-aspartate receptor antagonist, AP5. Nature 319, 774-776.

Morris, R. G., Garrud, P., Rawlins, J. N., and O'Keefe, J. (1982). Place navigation impaired in rats with hippocampal lesions. Nature 297, 681-683.

Moscovitch, M., Nadel, L., Winocur, G., Gilboa, A., and Rosenbaum, R. S. (2006). The cognitive neuroscience of remote episodic, semantic and spatial memory. Curr. Opin. Neurobiol. 16, 179-190.

Nadel, L., Campbell, J., and Ryan, L. (2007). Autobiographical memory retrieval and hippocampal activation as a function of repetition and the passage of time. Neural Plast. 2007, 90472.

O'Keefe, J., and Nadel, L. (1978). The Hippocampus as a Cognitive Map. Oxford: Oxford University Press.

Packard, M.G. (1999). Glutamate infused posttraining into the hippocampus or caudate-putamen differentially strengthens place and response learning. Proc. Natl. Acad. Sci. U.S.A. 96, 12881-12886.

Packard, M.G. (2009). Anxiety, cognition, and habit: a multiple memory systems perspective. Brain Res. 1293, 121-128.
Packard, M. G., and McGaugh, J.L. (1996). Inactivation of hippocampus or caudate nucleus with lidocaine differentially affects expression of place and response learning. Neurobiol. Learn. Mem. 65, 65-72.

Packard, M. G., and Teather, L. A. (1997). Double dissociation of hippocampal and dorsal-striatal memory systems by posttraining intracerebral injections of 2-amino-5- phosphonopentanoic acid. Behav. Neurosci. 111, 543-551.

Park, C. R., Campbell, A. M., Woodson, J. C., Smith, T. P., Fleshner, M., and Diamond, D. M. (2006). Permissive influence of stress in the expression of a U-shaped relationship between serum corticosterone levels and spatial memory errors in rats. Dose Response 4, 55-74.

Park, C. R., Zoladz, P. R., Conrad, C. D., Fleshner, M., and Diamond, D. M. (2008). Acute predator stress impairs the consolidation and retrieval of hippocampus-dependent memory in male and female rats. Learn. Mem. 15, 271-280.

Paxinos, G., and Watson, C. (1998) The Rat Brain: In Stereotaxic Coordinates. San Diego: Academic Press.

Poirier, G. L., Amin, E., and Aggleton, J. P. (2008). Qualitatively different hippocampal subfield engagement emerges with mastery of a spatial memory task by rats. J. Neurosci. 28, 1034-1045.

Pothuizen, H. H., Zhang, W. N., JongenRelo, A. L., Feldon, J., and Yee, B. K. (2004). Dissociation of function between the dorsal and the ventral hippocampus in spatial learning abilities of the rat: a within-subject, within-task comparison of reference and working spatial memory. Eur. J. Neurosci. 19, 705-712.

Rekkas, P. V., and Constable, R. T. (2005). Evidence that autobiographic memory retrieval does not become independent of the hippocampus: an fMRI study contrasting very recent with remote events. J. Cogn. Neurosci. 17, 1950-1961.

Riedel, G., Micheau, J., Lam, A. G., Roloff, E., Martin, S. J., Bridge, H., Hoz, L., Poeschel, B., McCulloch, J., and Morris, R. G. (1999). Reversible neural inactivation reveals hippocampal participation in several memory processes. Nat. Neurosci. 2, 898-905.

Roozendaal, B., Griffith, Q. K., Buranday, J., de Quervain, D. J., and McGaugh, J. L. (2003). The hippocampus mediates glucocorticoid-induced impairment of spatial memory retrieval: dependence on the basolateral amygdala. Proc. Natl.Acad. Sci. U.S.A. 100, 1328-1333. Rudy, J. W. (2009). Context representations, context functions, and the parahippocampal-hippocampal system. Learn. Mem. 16, 573-585.

Sandi, C. (2004). Stress, cognitive impairment and cell adhesion molecules. Nat. Rev. Neurosci. 5, 917-930.

Sandi, C., Loscertales, M., and Guaza, C. (1997). Experience-dependent facilitating effect of corticosterone on spatial memory formation in the water maze. Eur. J. Neurosci. 9, 637-642.

Sandi, C., and Pinelo-Nava, M. T. (2007). Stress and memory: behavioral effects and neurobiological mechanisms. Neural Plast. 2007, 78970.

Sandi, C., Woodson, J. C., Haynes, V. F., Park, C. R., Touyarot, K., LopezFernandez, M. A., Venero, C., and Diamond, D. M. (2005). Acute stress-induced impairment of spatial memory is associated with decreased expression of neural cell adhesion molecule in the hippocampus and prefrontal cortex. Biol. Psychiatry 57, 856-864.

Schwabe, L., Bohringer, A., and Wolf, O. T. (2009). Stress disrupts contextdependent memory. Learn. Mem. 16, 110-113.

Schwabe, L., Schachinger, H., de Kloet, E. R., and Oitzl, M. S. (2010a). Corticosteroids operate as a switch between memory systems. J. Cogn. Neurosci. 22, 1362-1372.

Schwabe, L., Wolf, O. T., and Oitzl, M. S. (2010b). Memory formation under stress: quantity and quality. Neurosci. Biobehav. Rev. 34, 584-591.

Schwabe, L., and Wolf, O. T. (2010). Learning under stress impairs memory formation. Neurobiol. Learn. Mem. 93, 183-188.

Shires, K. L., and Aggleton, J. P. (2008). Mapping immediate-early gene activity in the rat after place learning in a water-maze: the importance of matched control conditions. Eur. J. Neurosci. 28, 982-996.

Shyu, A. B., Belasco, J. G., and Greenberg, M. E. (1991). Two distinct destabilizing elements in the c-fos message trigger deadenylation as a first step in rapid mRNA decay. Genes Dev. 5, 221-231.

Spiers, H. J., and Maguire, E. A. (2007a). Decoding human brain activity during real-world experiences. Trends Cogn. Sci. (Regul. Ed.) 11, 356-365.

Spiers, H. J., and Maguire, E. A. (2007b). The neuroscience of remote spatial memory: a tale of two cities. Neuroscience 149, 7-27.

Strekalova, T., Zorner, B., Zacher, C., Sadovska, G., Herdegen, T., and Gass, P. (2003). Memory retrieval after contextual fear conditioning induces c-Fos and JunB expression in CA1 hippocampus. Genes Brain Behav. 2, 3-10.

Sutherland, R. J., Sparks, F. T., and Lehmann, H. (2010). Hippocampus and retrograde amnesia in the rat model: a modest proposal for the situation of systems consolidation. Neuropsychologia 48, 2357-2369.

Szapiro, G., Galante, J. M., Barros, D. M., Levi, D. S., Vianna, M. R., Izquierdo, L. A., Izquierdo, I., and Medina, J. H. (2002). Molecular mechanisms of memory retrieval. Neurochem. Res. 27, 1491-1498.

Teather, L.A., Packard, M. G., Smith, D. E., Ellis-Behnke, R. G., and Bazan, N. G. (2005). Differential induction of c-Jun and Fos-like proteins in rat hippocampus and dorsal striatum after training in two water maze tasks. Neurobiol. Learn. Mem. 84, 75-84.

Tronson, N. C., and Taylor, J. R. (2007). Molecular mechanisms of memory reconsolidation. Nat. Rev. Neurosci. 8, 262-275.

Tsoory, M. M., Vouimba, R. M., Akirav, I., Kavushansky, A., Avital, A., and Richter-Levin, G. (2008). Amygdala modulation of memory-related processes in the hippocampus: potential relevance to PTSD. Prog. Brain Res. 167, 35-51.

VanElzakker, M., Fevurly, R. D., Breindel, T., and Spencer, R. L. (2008). Environmental novelty is associated with a selective increase in Fos expression in the output elements of the hippocampal formation and the perirhinal cortex. Learn. Mem. 15, 899-908.

Vann, S. D., Brown, M. W., and Aggleton, J. P. (2000). Fos expression in the rostral thalamic nuclei and associated cortical regions in response to different spatial memory tests. Neuroscience 101, 983-991.

Vouimba, R. M., Munoz, C., and Diamond, D. M. (2006). Differential effects of predator stress and the antidepressant tianeptine on physiological plasticity in the hippocampus and basolateral amygdala. Stress 9, 29-40.

Weinberg, M. S., Grissom, N., Paul, E., Bhatnagar, S., Maier, S. F., and Spencer, R. L. (2010). Inescapable but not escapable stress leads to increased struggling behavior and basolateral amygdala c-fos gene expression in response to subsequent novel stress challenge. Neuroscience 170, 138-148.

White, N. M. (2009). Some highlights of research on the effects of caudate nucleus lesions over the past 200 years. Behav. Brain Res. 199, 3-23.

White, N. M., and McDonald, R. J. (1993). Acquisition of a spatial conditioned place preference is impaired by amygdala lesions and improved by fornix lesions. Behav. Brain Res. 55, 269-281. White, N.M., and McDonald, R. J. (2002). Multiple parallel memory systems in 
the brain of the rat. Neurobiol. Learn. Mem. 77, 125-184.

White, N. M., and Salinas, J. A. (2003). Mnemonic functions of dorsal striatum and hippocampus in aversive conditioning. Behav. Brain Res. 142, 99-107.

Wiltgen, B. J., Zhou, M., Cai, Y., Balaji, J., Karlsson, M. G., Parivash, S. N., Li, W., and Silva, A. J. (2010). The hippocampus plays a selective role in the retrieval of detailed contextual memories. Curr. Biol. 20, 1336-1344.

Woodson, J. C., Macintosh, D., Fleshner, M., and Diamond, D. M. (2003). Emotion-induced amnesia in rats: hippocampus-specific impairments, corticosterone-memory correlations and fear versus arousal effects on memory. Learn. Mem. 10, 326-336.
Yin, H. H., and Knowlton, B. J. (2004). Contributions of striatal subregions to place and response learning. Learn. Mem. 11, 459-463.

Zoladz, P. R., Campbell, A. M., Park, C. R., Schaefer, D., Danysz, W., and Diamond,D.M. (2006). Enhancement of long-term spatial memory in adult rats by the noncompetitive NMDA receptor antagonists, memantine and neramexane. Pharmacol. Biochem. Behav. 85, 298-306.

Zoladz, P. R., Park, C. R., Halonen, J. D., Salim, S., Alzoubi, K. H., Srivareerat, M., Fleshner, M., Alkadhi, K. A., and Diamond, D. M. (2011). Differential expression of molecular markers of synaptic plasticity in the hippocampus, prefrontal cortex and amygdala in response to spatial learning, predator exposure and stress-induced amnesia. Hippocampus. doi: 10.1002/ hipo.20922. [Epub ahead of print].

Zoladz, P. R., Woodson, J. C., Haynes, V. F., and Diamond, D.M.(2010).Activation of a remote (1-year old) emotional memory interferes with the retrieval of a newly formed hippocampus-dependent memory in rats. Stress 13, 36-52.

Conflict of Interest Statement: The authors declare that the research was conducted in the absence of any commercial or financial relationships that could be construed as a potential conflict of interest.

Received: 14 February 2011; paper pending published: 12 March 2011; accepted:
31 May 2011; published online: 24 June 2011.

Citation: VanElzakker MB, Zoladz PR, Thompson VM, Park CR, Halonen JD, Spencer RL and Diamond DM (2011) Influence of pre-training predator stress on the expression of c-fos mRNA in the hippocampus, amygdala, and striatum following long-term spatial memory retrieval. Front. Behav. Neurosci. 5:30. doi: 10.3389/ fnbeh.2011.00030

Copyright (C) 2011 VanElzakker, Zoladz, Thompson, Park, Halonen, Spencer and Diamond. This is an open-access article subject to a non-exclusive license between the authors and Frontiers Media SA, which permits use, distribution and reproduction in other forums, provided the original authors and source are credited and other Frontiers conditions are complied with. 